\title{
Rapid Increase of Ecological Forest and Fruit Forest for Two Mountain Settlements in the Upper Reaches of the Minjiang River, China
}

\author{
Zhengrong Yuan, Fucheng Li*, Yunwei Han, Xinwei Li, Yue Hu, Mengyuan Chen \\ School of Environment and Resource, Southwest University of Science and Technology, \\ Sichuan Mianyang 621010, China
}

Received: 18 October 2020

Accepted: 20 January 2021

\begin{abstract}
Mountainous areas are characterized by relative closure and vertical differentiation, and land use/land cover (LU/LC) are not continuous. There are few studies on the process of land use/land cover change (LUCC) at micro-scale in mountainous areas. In this study, two typical settlements (Jiashan and Jiuzi village) in the upper reaches of Minjiang River were selected to determine the range of accessibility and the maximum regional boundary of settlements based on the concept of ecological niche. Besides, through the method of remote sensing interpretation, transfer matrix, and dynamic index, the characteristics of micro scale LUCC in Jiashan and Jiuzi village from 1999 to 2014 were analyzed. During 1999 to 2014, the LU/LC of the two settlements changed drastically, among which the farmland area decreased significantly, while the ecological forest and fruit forest area increased significantly. In 2014, LU/LC types showed obvious characteristics of slope and vertical differentiation. The difference of hydrothermal conditions caused by the disparity of slope direction between the two settlements is the reasons for the variation in LU/LC distribution between the two settlements. From 1999 to 2014, the integrated dynamic index of LU/LC of Jiashan and Jiuzi village was $1.87 \%$ and 1.94\%, respectively, indicating that the LU/LC in alpine settlements at the upper reaches of Minjiang River was changing rapidly. In addition, we should be aware of the potential risks of food security and highquality sustainable development of fruit forests, which could be caused by returning farmland to forests in mountainous settlements.
\end{abstract}

Keywords: settlement, land use/land cover change (LUCC), dynamic index, the upper Minjiang River

*e-mail: 1fckind@163.com 


\section{Introduction}

Land use/land cover change (LUCC) contains information about the interaction between human activities and natural changes, which is an ideal starting point for the study of nature-human interaction interface [1-3]. In recent years, LUCC has become an important area for numerous scholars to reveal the relationship between global environmental changes and anthropogenic activities [4-6]. Some of the approaches involve are spatial-temporal process, driving mechanism investigations, process simulation, and environmental effects of LUCC [4, 7-11].

The upper reaches of the Minjiang River are the transition zone between the Tibetan Plateau and the Sichuan Basin, which is a concentrated distribution area of Tibetan, Qiang and Hui settlements in Sichuan Province. Compared with the Loess Plateau and the plain areas, the settlements in upper reaches of the Minjiang River are mostly concentrated on the slopes, and the available land for residents is extremely rare. Frequent regional geological disasters, severe soil erosion, and other issues have led to further reduction of available land and slow economic development [12]. Thus, the study on LUCC in typical settlements has an important strategic significance. Under the background of diverse settlement culture, humans have caused frequent and significant disturbances to the mountain ecological environment, making it the typical ecologically fragile area of the upper reaches of the Yangtze River [13-15]. For this special area, many researchers have carried out extensive studies on the spatial-temporal changes, driving forces, landscape patterns, and environmental effects of LUCC in the upper reaches of the Minjiang River [16-19]. Most of the studies consider the entire upper Minjiang River as a study area, and the time scale is mostly from 1974 to 2000 . In the upper reaches of the Minjiang River, projects of returning farmland to forest, ecological immigrant, and hydropower exploitation had been successfully implemented. Combined with the impact of earthquakes, the process of LUCC is extremely complicated. Therefore, research on LUCC in mountain settlements after 2000 is of great significance for revealing the spatial-temporal pattern and the reason of LUCC and also for discovering prominent problems in $\mathrm{LU} / \mathrm{LC}$ at a certain point in time.

Niche is a term describing the role of a species or population in its ecosystem [20]. The ecological niches in the mountain settlement refer to the geographical location of human settlements in the mountain ecosystem and the space of resources that can be used by their residents. The ecological niches in the mountain settlement reflect the functional geographical characteristics of settlements. The study of LUCC based on the ecological niches in the mountain settlement in the upper reaches of the Minjiang River can effectively reveal dynamic change process in micro-scale LU/LC in mountainous areas and the interaction pattern between human activities and the external environment.
In 1999, Li County launched the pilot project of returning farmland to forests, and by 2002, a total of 225 ha area was completed (http://www.abadaily.com). The Jiashan and Jiuzi villages were selected as the typical settlements to study the change characteristics of the ecological niches, and the reasons are as follows: (i) the study area is located in the Zagunao River in the upper reaches of Minjiang River, with extremely special geological, climatic, hydrological and settlement characteristics; (ii) the main source of income for Jiashan and Jiuzi villages comes from cultivation in the history and in 1999, Jiashan and Jiuzi village of Li County implemented the policy of "returning farmland to forest" for the first time.

Thus, this study aims to investigate: (i) LUCC in high mountain settlements under the influence of the policy to return farmland to forests; (ii) changes in slope and elevation of ecological forest land caused by returning farmland to forests; and (iii) the LU/LC transfer rate and dynamic characteristics of high mountain settlements based on the settlement ecological niches scale.

\section{Material and Methods}

\section{Study Area}

The study area, located in Jiashan Village (Jiashan) and Jiuzi Village (Jiuzi), Li County, in the upper reaches of the Minjiang River in Sichuan Province, China, is a mountainous region in the eastern part of the Tibetan Plateau (103.43-103.45E, 31.52-31.55N). Particularly, the study area is located on the boundary between the firststep and second-step in three gradient terrain of China. The special geomorphic features and the rapid river incision feature cause most of the settlements in this area to be distributed on the slope in the river valley.

The ecological niche areas of Jiashan and Jiuzi were 573.90 ha and 267.21 ha, respectively. The determination of the ecological niche boundary was mainly based on the interpretation of the river, the foot of the slope, the gully and the texture and color difference of the remote sensing image. The rivers and the foot of the slope were used as the lower boundary of the ecological niche, and the other boundaries were determined by the difference in texture between natural forests and artificial forests disturbed by human activities. According to China meteorological data service center (http://data.cma.cn/ en), the study area has a plateau monsoon climate with mean annual temperature of $11.4^{\circ} \mathrm{C}$, average annual rainfall of $619.2 \mathrm{~mm}$, and average annual evaporation of $987 \mathrm{~mm}$ for the period between 1981 and 2010 .

\section{Data Source}

The Advanced Spaceborne Thermal Emission and Reflection Radiometer (ASTER) global digital elevation model (GDEM) data was acquired from geospatial 
data cloud (http://www.gscloud.cn/). SPOT-4 image in 1999 (the resolution of panchromatic band is $10 \mathrm{~m}$, the resolution of multispectral band is $20 \mathrm{~m}$ ) and the SPOT6 satellite remote sensing image in 2014 (the resolution of panchromatic band is $1.5 \mathrm{~m}$, the resolution of multispectral band is $6 \mathrm{~m}$ ) were acquired from Airbus company (https://www.intelligence-airbusds.com/en/ 4871-geostore-ordering).

\section{Research Method}

The pre-processing of remote sensing image was conducted by using ERDAS IMAGINE v. 9.2 and ArcGIS v.10.2 software. In addition, real-time online images from Google Earth on-site interview and field investigation were used to distinguish the relative position relationships between ground objects. According to the technical specification for land use survey in China (1984) and the actual situation in study area, we divide the gradient range into six grades and the altitude range into seven grades. Then obtain the LU/LC types and areas in different periods. The characteristics of LUCC was reflected by the transfer matrix and dynamic index.

The LU/LC transfer matrix, called the Markov transfer matrix, can reflect the mutual transformation of LU/LC types in a certain area from one type to another within a certain period of time. It is a widely used method for studying the characteristics, direction, and structure of LUCC and it can describe structural characteristics of LU/LC, and the source of various types during the study period. Furthermore, it can generate a transition probability matrix, and then analyze the hot spots of land use change [21].

$$
w=\left[\begin{array}{cccc}
w_{11} & w_{12} & \ldots & w_{1 n} \\
w_{21} & w_{22} & \cdots & w_{2 n} \\
\vdots & \vdots & \ddots & \vdots \\
w_{n 1} & w_{n 2} & \cdots & w_{n n}
\end{array}\right]
$$

In the formula, $w$ represents the LU/LC area of different types; $w_{i j}$ represents the area of LU/LC $i$ transferred to LU/LC type $j$ before the transfer, and $n$ represents the number of types before and after the LU/ LC transfer; $i, j(i, j=1,2, \ldots, n)$, respectively represent different types of LU/LC transfer process.

The dynamic LUCC index quantitatively describes the rate of LUCC and can objectively reflect dynamic change in LU/LC types and the intensity of land use changes [22]. The land use dynamic index includes a single dynamic index of LU/LC and an integrative dynamic index of LU/LC [23, 24]. A single dynamic index of land use describes the magnitude and speed of a specific land use change (Eq. (2)), and integrated dynamics index of land use describes the speed of the land use system in the study area (Eq. (3)) is [20, 22]:

$$
K=\frac{U_{b}-U_{a}}{U_{a}} \times \frac{1}{T} \times 100 \%
$$

In the equation (2), $K$ represents the dynamic index of land use during the period of time. $U_{a}$ and $U_{b}$ are the area of a land use type at the beginning and end of the study; $T$ is the period of time; where, the unit of $T$ is year, $K$ is the annual rate of one land use change in the study area.

$$
L_{C}=\left|\frac{\sum_{i=1}^{n} \Delta L u_{i-j}}{2 \sum_{i=0}^{n} L u_{i}}\right| \times \frac{1}{T} \times 100 \%
$$

In the above equation, $L u_{i}$ is the area of LU/LC type $i$ at the beginning of the study period; $\Delta L u_{i-j}$ is absolute value of the area that LU/LC type $i$ converted to other land; $T$ is the period of monitoring time; where, the unit of $T$ is year, $L c$ is the annual rate of LUCC in the study area.

\section{Results}

\section{Land Use/Land Cover Change}

The ecological niche areas of Jiashan and Jiuzi were 573.90 ha and 267.21 ha, respectively (Fig. 1). The type of LU/LC of the two settlements changed drastically from 1999 to 2014, in which the area of farmland decreased significantly, while the area of ecological forest land and fruit forest land increased significantly (Table 1). The decline in farmland areas of Jiashan and Jiuzi accounted for $32.15 \%$ and $36.26 \%$ of the total ecological niche area, respectively, while the forest area increased $22.87 \%$ and $5.23 \%$ of the two total ecological niche area, respectively. The main varieties of fruit forest are plum, apple, cherries, and the area of fruit forest land accounted for $16.56 \%$ and $24.48 \%$ of the two ecological niche total area, respectively. The returning farmland to forest area of in Jiashan, which is located on a shady slope, was significantly larger than that of Jiuzi on sunny slope, especially the increased in the area of ecological forest land of Jiashan was 9.4 times than that of Jiuzi.

\section{Slope Gradient and Vertical Differentiation of Forest Land Changes}

From 1999 to 2014, ecological forest land and fruit forest land area of two settlements had changed significantly in terms of slope gradient (Table 2). In 1999, the ecological forest land of two settlements was distributed on each gradient section, and the area showed a dominant distribution among the slope of $25^{\circ}-35^{\circ}$, while the distribution was the least among the gradient of $0^{\circ}-6^{\circ}$. In 2014, ecological forest land showed an increasing trend in almost all gradient. 
a)

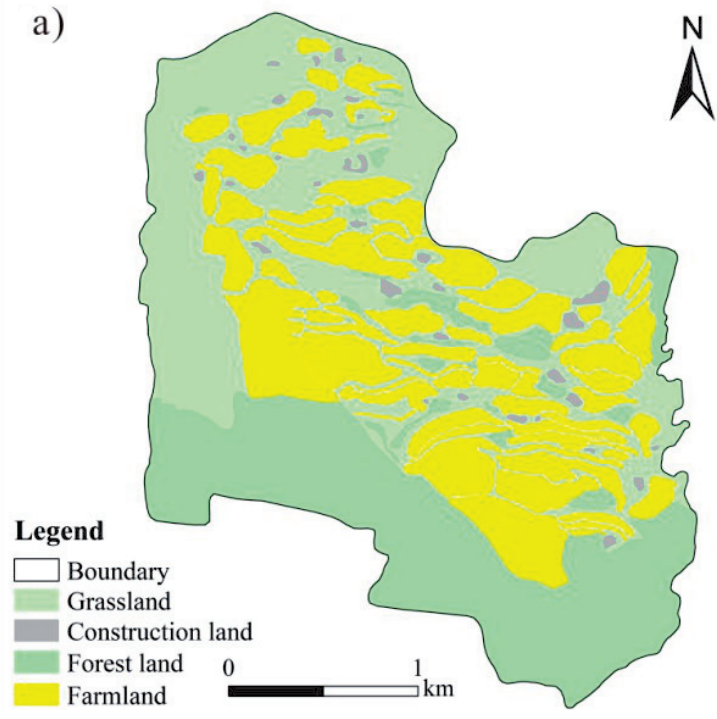

c)

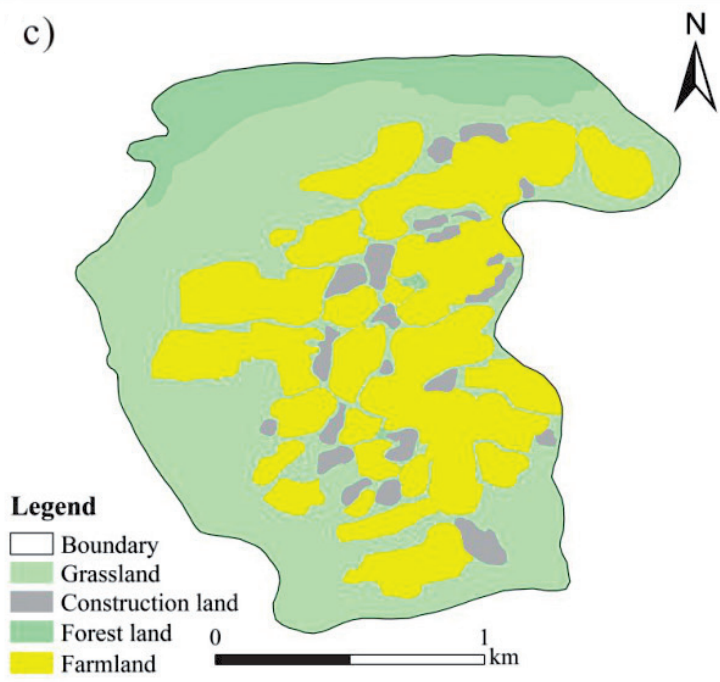

b)

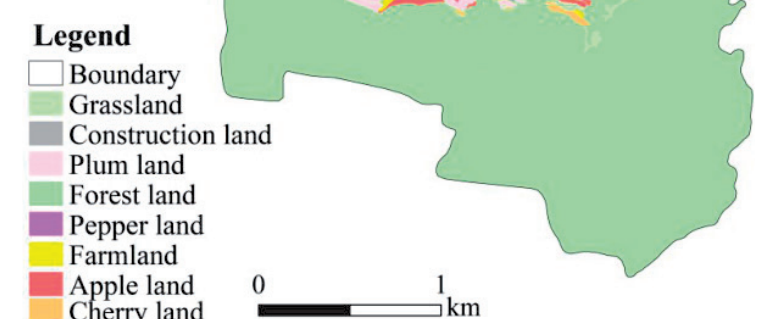

Cherry land $\mathrm{km}$

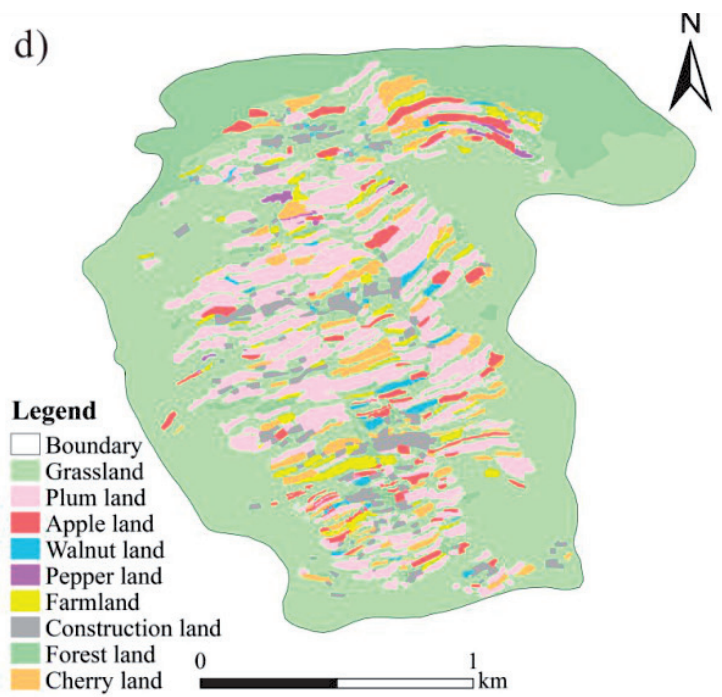

Fig. 1. The land use/land cover maps of Jiashan and Jiuzi Village in 1999 and 2014. a) LU/LC map of Jiashan, 1999. b) LU/LC map of Jiashan, 2014. c) LU/LC map of Jiuzi, 1999. d) LU/LC map of Jiuzi, 2014.

Table 1. Land use/land cover (LU/LC) patterns and change characteristics in 1999 and 2014.

\begin{tabular}{|c|c|c|c|c|c|c|c|c|}
\hline \multirow{2}{*}{ LU/LC type } & \multicolumn{3}{|c|}{1999} & \multicolumn{2}{c|}{2014} & \multicolumn{2}{c|}{$1999-2014$ (ha) } & \multicolumn{2}{c|}{$1999-2014(\%)$} \\
\cline { 2 - 11 } & \multicolumn{4}{|c|}{ Area (ha) } & \multicolumn{2}{c|}{ Change of area } & \multicolumn{2}{c|}{ Change of proportion } \\
\cline { 2 - 11 } & JS & JZ & JS & JZ & JS & JZ & JS & JZ \\
\hline Grassland & 205.83 & 125.62 & 163.97 & 146.26 & -41.86 & 20.64 & 20.64 & 7.72 \\
\hline Farmland & 189.83 & 102.72 & 5.33 & 5.83 & -184.50 & -96.89 & -96.89 & -36.26 \\
\hline Ecological forest land & 169.05 & 24.68 & 300.32 & 38.65 & 131.27 & 13.97 & 13.97 & 5.23 \\
\hline Construction land & 9.19 & 14.19 & 9.22 & 11.06 & 0.03 & -3.13 & -3.13 & -1.17 \\
\hline Plum land & - & - & 41.45 & 43.43 & 41.45 & 43.43 & 43.43 & 16.25 \\
\hline Apple land & - & - & 27.28 & 8.10 & 27.28 & 8.10 & 8.10 & 3.03 \\
\hline Cherry land & - & - & 25.46 & 10.90 & 25.46 & 10.90 & 10.90 & 4.08 \\
\hline Pepper land & - & - & 0.87 & 0.87 & 0.87 & 0.87 & - & 0.33 \\
\hline Walnut land & - & - & - & 2.11 & - & 2.11 & - & 0.79 \\
\hline
\end{tabular}

Notes: JS is Jiashan village and JZ is Jiuzi village. 
The ecological forest land increased more in the slope of $25-65^{\circ}$, and most of the fruit forest land was distributed in the gentle gradient section which was consistent with the policy of returning farmland to forests requiring high-slope lands to forest. Plum trees were planted on slope gradient of $0^{\circ}-35^{\circ}$, in which most of plum trees were planted on slopes of $6^{\circ}-15^{\circ}$, and a small number were also planted on slope gradient of $25^{\circ}-35^{\circ}$. The planting gradients of apple trees, cherry trees and pepper trees were all lower than $25^{\circ}$, especially concentrated in the range of $0^{\circ}-6^{\circ}$.

During 1999-2014, the changes of ecological forest land and fruit forest land in the two settlement areas showed obvious vertical differentiation characteristic (Table 2). In 1999, the ecological forest land of Jiashan was distributed from $1400 \mathrm{~m}$ to $2800 \mathrm{~m}$ above sea level, most of which distributed in the altitude of $2200-2600 \mathrm{~m}$, and it was accounted for $77 \%$ of the total ecological forest land area. Meanwhile, the forest land of Jiuzi was distributed from 1800-2600 m above sea level, most of which distributed in the altitude of $2400-2600 \mathrm{~m}$, and it was accounted for $84 \%$ of the total forest area. In 2014, the ecological forest land area distribution range of the Jiashan and Jiuzi was 1600-2800 $\mathrm{m}$ and 1600-2600 m, respectively. Most of the ecological forest land of the Jiashan was distributed in the altitude of $1800-2600 \mathrm{~m}$, while the Jiuzi was distributed in the altitude of 2200-2600 m. The vertical distribution of cherry trees, apple trees and plum trees in Jiashan was more concentrated than that in Jiuzi. In Jiashan, the fruit forests were located at an altitude range of 1400-2200 m, while in Jiuzi they were distributed within the altitude range of 1400-2600 m.

\section{Land Use/Land Cover Type Change Characteristics}

The land use/land cover (LU/LC) transition matrix and LU/LC transfer rate matrix of Jiashan are shown in Table 3. During the study period, the overall characteristics of the LU/LC in the Jiashan were: $52.93 \%$ of the original grassland was converted to other types of land, of which $32.65 \%$ of grassland was converted to forestland; $9.59 \%$ of the original ecological forest land was converted to other types of land, of which $4.17 \%$ ecological forest land was converted to grassland, the original farmland was mainly converted to ecological forest land, and the conversion rate was high (40.82\%). Therefore, from 1999 to 2014, the area of grassland and farmland had decreased by 109.13 ha and 188.17 ha, respectively, and the area of ecological forest land increased by 147.50 ha. The area of construction land has changed a little, and the area of fruit forest land was increased significantly. The transfer rate of the original ecological farmland was the largest (99.1\%), while the transfer rate of the original ecological forest land was the smallest $(9.59 \%)$.

The LU/LC transition matrix and LU/LC transfer rate matrix of Jiuzi from 1999 to 2014 are shown in Table 3. It was observed that, $22.69 \%$ of the original grassland of Jiuzi was converted to other types of land, of which $12.34 \%$ of grassland was converted to

Table 2. Differentiation of forest land types on different gradient and Elevation (ha).

\begin{tabular}{|c|c|c|c|c|c|c|c|c|c|c|c|c|c|}
\hline & \multirow[t]{3}{*}{ Year } & \multirow{2}{*}{\multicolumn{2}{|c|}{$\begin{array}{l}1999 \\
E F L\end{array}$}} & \multicolumn{10}{|c|}{2014} \\
\hline & & & & \multicolumn{2}{|c|}{ EFL } & \multicolumn{2}{|c|}{ PL } & \multicolumn{2}{|c|}{$\mathrm{AL}$} & \multicolumn{2}{|c|}{ ChL } & \multicolumn{2}{|c|}{$\mathrm{PeL}$} \\
\hline & & JS & $\mathrm{JZ}$ & JS & $\mathrm{JZ}$ & JS & $\mathrm{JZ}$ & JS & $\mathrm{JZ}$ & JS & $\mathrm{JZ}$ & JS & $\mathrm{JZ}$ \\
\hline \multirow{6}{*}{$\begin{array}{c}\text { Gradient } \\
\left(^{\circ}\right)\end{array}$} & $0-6$ & 3.20 & 0.10 & 2.70 & 3.10 & 17.70 & 13.80 & 17.20 & 6.40 & 16.30 & 7.30 & 0.90 & 0.60 \\
\hline & $6-15$ & 15.20 & 2.90 & 20.80 & 6.10 & 19.40 & 19.80 & 9.40 & 2.00 & 8.80 & 3.70 & - & 0.10 \\
\hline & $15-25$ & 38.20 & 7.70 & 73.40 & 10.00 & 4.80 & 9.90 & 0.70 & 0.30 & 0.70 & 0.10 & - & - \\
\hline & $25-35$ & 55.10 & 8.30 & 106.50 & 11.50 & 0.30 & 0.80 & - & - & - & - & - & - \\
\hline & $35-45$ & 33.50 & 3.20 & 62.20 & 4.50 & - & - & - & - & - & - & - & - \\
\hline & $45-65$ & 23.30 & 2.30 & 34.20 & 4.20 & - & - & - & - & - & - & - & - \\
\hline \multirow{7}{*}{$\begin{array}{c}\text { Elevation (100 } \\
\mathrm{m})\end{array}$} & $14-16$ & 0.42 & - & - & - & 2.70 & 0.42 & 0.84 & - & 0.76 & 0.59 & 0.17 & - \\
\hline & $16-18$ & 3.45 & - & 8.84 & 0.51 & 10.11 & 1.77 & 2.86 & 1.52 & 4.13 & 6.15 & 0.17 & - \\
\hline & $18-20$ & 8.51 & 0.08 & 39.84 & 1.94 & 6.15 & 2.27 & 10.95 & 1.60 & 11.12 & 9.26 & 0.34 & - \\
\hline & $20-22$ & 19.79 & 1.18 & 66.88 & 3.45 & 6.82 & 3.12 & 12.63 & 1.77 & 26.11 & 15.08 & 0.25 & - \\
\hline & $22-24$ & 61.99 & 2.78 & 110.42 & 10.87 & - & 2.19 & - & 2.36 & - & 11.54 & - & 0.67 \\
\hline & $24-26$ & 67.13 & 20.55 & 66.62 & 22.57 & - & 1.35 & - & 1.43 & - & 1.60 & - & - \\
\hline & $26-28$ & 7.16 & - & 7.33 & - & - & - & - & & - & & - & - \\
\hline
\end{tabular}

Notes: JS is Jiashan village and JZ is Jiuzi village. EFL is ecological forest land, PL is plum land, AL is apple land, ChL is cherry land and PeL is pepper land 
Table 3. The transition matrix and the transfer rate (TR) matrix of LU/LC typed in Jiashan and Jiuzi.

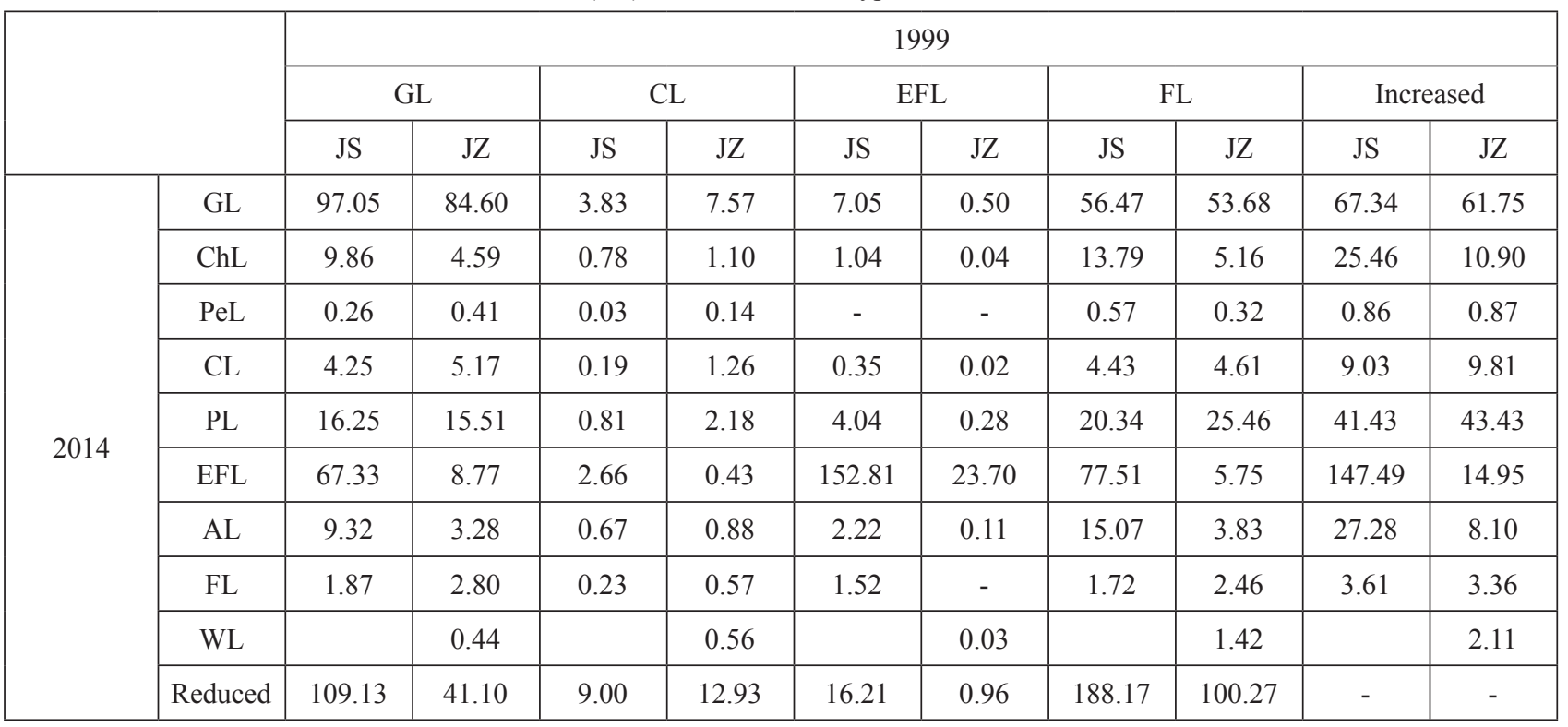

Notes: GL is grassland, $\mathrm{ChL}$ is cherry land, $\mathrm{PeL}$ is pepper land, $\mathrm{CL}$ is construction land, $\mathrm{PL}$ is plum land, EFL is ecological forest land, AL is apple land, FL is farmland and WL is walnut land.

plum-tree land; only $3.89 \%$ of the original ecological forest land was converted to other types of land, of which $2.01 \%$ ecological forest land was converted to grassland. The original farmland was mainly converted to grassland and the conversion rate was high (52.25\%). From 1999 to 2014, the area of farmland in the Jiuzi was greatly reduced, and the area of fruit forest land was increased significantly. The transfer rate of the original farmland and ecological forest land of the Jiuzi was similar to that of the Jiashan, and the transfer rate of the original farmland and ecological forest land was $97.6 \%$ and $3.9 \%$, respectively.

\section{Land Use/Land Cover Dynamics}

The area of farmland in the Jiashan and the Jiuzi decreased the fastest with the values of $-6.48 \%$ and $-6.29 \%$, respectively (Table 4 ). The area of ecological forest land increased fastest with the values of 5.18\% and $3.78 \%$, respectively. The integrated dynamic index of LU/LC for Jiashan and Jiuzi was $1.87 \%$ and $1.94 \%$, respectively, indicating that the LUCC in this area was in a stage of rapid development.

\section{Discussion}

The ecological niches in the settlements of Jiashan and Jiuzi were selected as the cases in this study, which provides a new perspective for analyzing the characteristics of LUCC in mountainous areas. Generally, previous studies focused on two types of research objects for the research of LUCC, which includes the administrative districts and the hydrological catchment $[25,26]$. Firstly, the studies based on administrative districts was beneficial for analyzing the socio-economic driving force of LUCC and it is more suitable for plain or hilly areas [27]. Secondly, the studies based on the hydrological catchment was convenient to the analysis of LU/LC ecosystem services and management $[8,28]$. However, in this study, the ecological niches in settlement were selected as the third type of research objects in the research of LUCC. Ecological niche in the settlement means a place or situation that is especially well suited to an individual or inanimate object, and it is an important theory of ecology, which can measure the frames of continuous change process in ecological relations and clearly reflect the succession and development of land ecosystem [29]. The ecological niches in settlement were most strongly and frequently affected by human activities and the influences of LUCC outside the settlements can be effectively revealed. Studies based on this new perspective can effectively reveal the micro-scale LUCC process and the coupling mechanism between human and LU/LC in mountainous areas. Consequently, the LUCC in Jiashan and Jiuzi settlements were affected by human activities, while the land changes of woodland and grassland, which were the main types of LU/LC outside the settlement, were controlled by the natural conditions.

The area of farmland in Jiashan and Jiuzi settlements decreased significantly from 1999 to 2014, while the area of ecological forest land and fruit forest land were increased significantly. The decreased area of farmland in Jiashan and Jiuzi settlements accounted for $32.15 \%$ and $36.26 \%$, respectively of the total area of the ecological niches in the settlements, while the increased area accounted for $39.43 \%$ and $29.71 \%$, respectively. The main driving force of this change was the project 
Table 4. Dynamic degree index in study area.

\begin{tabular}{|c|c|c|}
\hline & $\begin{array}{c}\text { Jiashan Village } \\
(\%)\end{array}$ & $\begin{array}{c}\text { Jiuzi Village } \\
(\%)\end{array}$ \\
\hline Grassland & -1.35 & 1.10 \\
\hline Construction land & 0.02 & -1.47 \\
\hline Ecological forest land & 5.18 & 3.78 \\
\hline Farmland & -6.48 & -6.29 \\
\hline
\end{tabular}

of transferring farmland to forests implemented in 1999 to improve the ecological environment. The policy requires farmers to convert farmland with a gradient greater than $25^{\circ}$ into ecological forests land or fruit forest land and the institutional subsidies directly increased the income of farmers [30]. The slope distribution characteristics of ecological forest land and fruit forest land in 2014 showed that almost all farmland with a gradient greater than $25^{\circ}$ in Jiashan and Jiuzi was converted to ecological forest land, which indicates the policy was well implemented in the study area. Besides, the local government strongly encourages the farmers to develop the fruit industry in order to accelerate the process of poverty alleviation. Due to the long sunlight, high altitude, and large temperature difference between day and night, the study area is very suitable for planting fruit forest. The cherries, apples and plums produced in the study area have become well-known fruits. In addition, the prices of these fruits are considerably higher than other areas, which further increases the family income of farmers and contributes to the poverty alleviation in mountainous settlements.

The policy of transferring farmland to forests has resulted in obvious vertical differentiation of ecological forest land and fruit forest land. The increased ecological forest land was mainly concentrated in the high-altitude area of $2200-2600 \mathrm{~m}$, and the fruit forest land was most concentrated in $1800-2200 \mathrm{~m}$. The main reasons for the differentiation phenomenon because of poor traffic conditions, relatively insufficient infrastructure, and high living costs in high-altitude areas, making the high-altitude areas the first choice for converting farmland to ecological forest land. With the progress of converting farmland to forests, the disturbance of human activities in high-altitude areas will gradually decrease, and the density of forests will gradually increase, which will cause the upper boundary of the ecological niches in the settlement to move downward. The fruit forest is distributed in the middle region of the mountains, mainly because the study area is located in the semi-arid area with gentle slope gradient, and the hydrothermal conditions are very suitable for fruit forest growth. Besides, the results also showed that the fruit trees in Jiashan was distributed with an altitude of 1400-2200 m, while the fruit forest in Jiuzi was distributed in a wider altitude range of 140-2600 m. The difference in elevation of fruit forest between Jiashan and Jiuzi was mainly due to the different hydrothermal conditions caused by the slope orientation of the two settlements. The Jiashan is located on a shaded slope and Jiuzi is located on a sunny slope. The sunny slope has sufficient sunlight, which promotes growth of fruit forest and offsets part of the inhibition effect caused by the decreasing in temperature as the altitude increased. Moreover, the water conditions in the high altitude area were relatively better [31]. Water conditions are an important factor for the development of the ecological fruit industry in this area. Field surveys show that the Jiashan in shady slope has better water conditions than Jiuzi in sunny slope, which provides a favorable condition in Jiashan in the low-altitude area.

From 1999 to 2014, the LU/LC dynamic index of farmland in Jiashan and Jiuzi were $-6.48 \%$ and $-6.29 \%$, respectively, and the LU/LC dynamic index of ecological forest land was $5.18 \%$ and $3.78 \%$, respectively. There is obvious difference of the dynamics index in different geomorphic areas in China (Fig. 2). The area of farmland decreased in the four regions, but the average level of farmland dynamic index in study area (-6.385) is much higher than that of the Loess Plateau area (-0.34) [32-35], the hilly area (-1.03) [36-40] and the plain area (-1.84) [41-45]. Additionally, the area of ecological forest land increased in the four regions, but average level of forest land dynamic index in study area (4.48) is much higher than that of the Loess Plateau area (0.03), the hilly area (0.8) and the plain area $(0.65)$. These results indicate that the LU/LC in alpine settlements in the upper reaches of the Minjiang River is rapidly transforming from farmland to ecological forest land and fruit forest land. At the same time, it also shows that using the research scale of ecological niches to analyze the LUCC in mountainous areas can make the results more sensitive to reflect the dynamic process of LUCC at the micro-scale and the interaction between human activities and the external ecological environment from the micro scale.

The study area belongs to an arid area in terms of climate and a mountain area in terms of geomorphology. The massive reduction of farmland will restrict the continuous growth of economic benefits of transferring farmland to forests, which will lead to increase risks. This risk comes from two aspects, mainly includes the food security risk [46] and high-quality sustainable development risk of fruit forest. Firstly, the reduction of farmland was mainly caused by policy-based conversion of farmland to forests and grasslands and farmers' abandonment of farmland. The policy-based conversion is the main factor, and the farmers' abandonment of farmland has gradually occurred in recent years. The livelihoods of farmers in the study area are mainly derived from non-agricultural industries such as fruit forest planting, livestock breeding, migrant working, cordyceps digging, and rural tourism. And the grain in study area has changed from self-sufficient model to a model that mainly relies on external input. In addition, the study area has the characteristics of high mountains and steep slopes, frequent geological disasters, and 


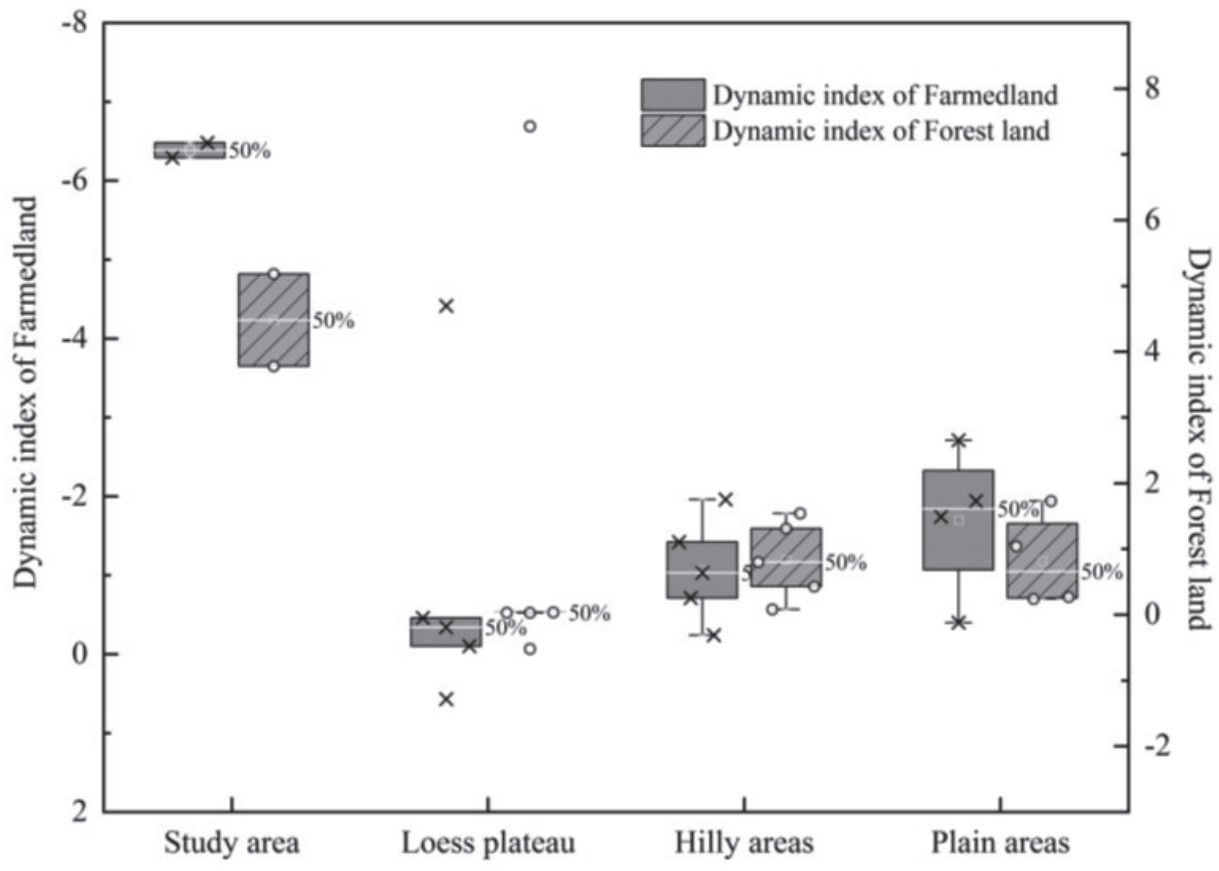

Fig. 2. Dynamic index of farmland and ecological forest land in different geomorphic areas.

heavy snow closures in winter, which lead to difficult transportation and high food crises. Secondly, due to the large amount of evaporation in the arid valley, the shortage of soil moisture seriously restricts the harvest of the fruit forest. The area of fruit forest has continued to expand, but the development of agricultural irrigation facilities has been lagging behind, which will bring serious economic losses to farmers in years of extreme drought. In addition, the management of fruit forest puts forward higher requirements on farmers, such as pest control and variety upgrade.

Taking Jiashan and Jiuzi, the typical settlements on the eastern edge of the Tibet Plateau, as the research objects, we analyzed the characteristics of LUCC from 1999 to 2014 and discussed their influencing factors. However, land use changes not only directly affect the changes in land cover and ecological evolution, but also affect global climate change by affecting soil organic carbon [5, 47, 48]. Therefore, it is still necessary to study the universality of our findings in other countries and the impact of economic fruit forest types on the cumulative effect of soil organic carbon and total nitrogen in the future.

\section{Conclusions}

From 1999 to 2014, forestland changes showed obvious characteristics of slope and vertical direction in typical settlements in the upper reaches of Minjiang River. After 1999, the area of forestland and economic fruit forest land was increased significantly, farmland area was decreased greatly. The growth of the economic demand resulted in conversion of farmland in the study area to economic fruit forest in the process of transition of farmland to forest. Most of the economic fruit forest land area was distributed in the gentle slope and low altitude areas, where, the ecological forest land was distributed dominantly in the slope area ranges from $25-35^{\circ}$ and the high-altitude area. However, due to the difference of the topographical and hydrothermal conditions in the two settlements, the distributing characteristics of fruit forest land has significant difference along altitude. The higher dynamic land use index of alpine settlements in the upper reaches of Minjiang River sensitively reflects the process of dynamic LUCC and the interaction effect between human activities and external environment at the micro-scale perspective of ecological niches in the settlements of mountainous areas. Besides, the risk of food security and high-quality sustainable development of fruit forest in the arid valley of the upper Minjiang River are worthy of consideration.

\section{Acknowledgments}

The research was supported by the National Natural Science Foundation of China (Grant No.41401301), and the Science and Technology Project of Mianyang City (Project no. 2018YFZJ019).

\section{Conflicts of Interest}

The authors declare no conflict of interest. 


\section{References}

1. JONATHAN A.F. Global consequences of land use. Science (New York, N.Y.), 5734 (309), 2005.

2. TURNER B.L., LAMBIN E.F., REENBERG A. The emergence of land change science for global environmental change and sustainability. Proceedings of the National Academy of Sciences, 104 (52), 20666, 2007.

3. YIRAN G.A.B., ABLO A.D., ASEM F.E. Urbanisation and domestic energy trends: Analysis of household energy consumption patterns in relation to land-use change in peri-urban Accra, Ghana. Land Use Policy, 99, 105047, 2020.

4. GARG K.K., ANANTHA K.H., NUNE R., AKURAJU V.R., SINGH P., KRISHNA G.M., RAGAB R. Impact of land use changes and management practices on groundwater resources in Kolar district, Southern India. Journal of Hydrology: Regional Studies, 31, 100732, 2020.

5. SONG XIAO-PENG., HANSEN MATTHEW C., STEHMAN STEPHEN V., POTAPOV PETER V., TY UKAVINA ALEXANDRA., VERMOTE ERIC F., TOWNSHEND JOHN R. Global land change from 1982 to 2016. Nature, 2018.

6. ZHANG X., SONG W., LANG Y., FENG X., YUAN Q., WANG J. Land use changes in the coastal zone of China's Hebei Province and the corresponding impacts on habitat quality. Land Use Policy, 99, 104957, 2020.

7. JIANG Y.J., YUAN D.X., ZHANG C., KUANG M.S., WANG J.L., XIE S.Y., HE R.S. Impact of land-use change on soil properties in a typical karst agricultural region of Southwest China: a case study of Xiaojiang watershed, Yunnan. Environmental Geology, 50 (6), 911, 2006.

8. TANG J., LI Y., CUI S., XU L., DING S., NIE W. Linking land-use change, landscape patterns, and ecosystem services in a coastal watershed of southeastern China. Global Ecology and Conservation, 23, e01177, 2020.

9. XI J., ZHAO M., GE Q., KONG Q. Changes in land use of a village driven by over 25 years of tourism: The case of Gougezhuang village, China. Land Use Policy, 40, 119, 2014.

10. XING W., QIAN Y., GUAN X., YANG T., WU H. A novel cellular automata model integrated with deep learning for dynamic spatio-temporal land use change simulation. Computers \& Geosciences, 137, 104430, 2020.

11. NOSZCZYK T., RUTKOWSKA A., HERNIK J. Determining Changes in Land Use Structurein Małopolska Using Statistical Methods. Polish Journal of Environmental Studies, 26 (1), 211, 2017.

12. TIWARI P. Land use changes in Himalaya and their impacts on environment, society and economy: A study of the Lake Region in Kumaon Himalaya, India. Advances in Atmospheric Sciences, 25 (6), 1029, 2008.

13. FANG Y., FAN J., SHEN M., SONG M. Sensitivity of livelihood strategy to livelihood capital in mountain areas: Empirical analysis based on different settlements in the upper reaches of the Minjiang River, China. Ecological Indicators, 38, 225, 2014.

14. ZHANG H., MENG C., WANG Y., WANG Y., LI M. Comprehensive evaluation of the effects of climate change and land use and land cover change variables on runoff and sediment discharge. Sci Total Environ, 702, 134401, 2020.

15. LI F., ZHAO L., WANG Q., FAN M., WANG H. Land use change characteristics of settlement ecological niche in the upper reaches of Min River. Chinese agricultural science bulletin, 32 (20), 85, 2016.
16. HU X., WU C., HONG W., QIU R., LI J., HONG T. Forest cover change and its drivers in the upstream area of the Minjiang River, China. Ecological Indicators, 46, 121, 2014.

17. WENGUANG Z., YUANMAN H., JINCHU H., YU C., JING Z., MIAO L. Impacts of land-use change on mammal diversity in the upper reaches of Minjiang River, China: Implications for biodiversity conservation planning. Landscape and Urban Planning, 85 (3-4), 195, 2008.

18. ZHANG M., WEI X., SUN P., LIU S. The effect of forest harvesting and climatic variability on runoff in a large watershed: The case study in the Upper Minjiang River of Yangtze River basin. Journal of Hydrology, 464-465, 1, 2012.

19. HE X.-Y., ZHAO Y.-H., HU Y.-M., CHANG Y., ZHOU,Q.-X. Landscape Changes from 1974 to 1995 in the Upper Minjiang River Basin, China. Pedosphere, 16 (3), 398, 2006.

20. MARTÍNEZ-GORDILLO D., ROJAS-SOTO O., ESPINOSA DE LOS MONTEROS A. Ecological niche modelling as an exploratory tool for identifying species limits: An example based on Mexican muroid rodents. Journal of Evolutionary Biology, 23 (2), 259, 2010.

21. ZHAO L., FAN X. Effects of Land Use Changes on Ecosystem ServiceValues: A Case Study in Guilin, China. Polish Journal of Environmental Studies, 29 (2), 1483, 2020.

22. HEMMAVANH C., YE Y., YOSHIDA A. Forest land use change at Trans-Boundary Laos-China Biodiversity Conservation Area. Journal of Geographical Sciences, 20 (6), 889, 2010

23. LONG H., LIU Y., WU X., DONG G. Spatio-temporal dynamic patterns of farmland and rural settlements in Su-Xi-Chang region: Implications for building a new countryside in coastal China. Land Use Policy, 26 (2), 322, 2009.

24. LI S.-H., JIN B.-X., ZHOU J.-S., WANG J.-L., PENG S.-Y. Analysis of the SpatiotemporalLand-Use/Land-Cover Changeand its Driving Forces in Fuxian LakeWatershed, 1974 to 2014. Polish Journal of Environmental Studies, 26 (2), 671, 2017.

25. HAN Y., NIU J., WU F. Land-use changes in the small watershed of the Loess Plateau, hilly-gully region, China. Journal of Forestry Research, 26 (1), 91, 2015.

26. BORRELLI P., ROBINSON D.A., FLEISCHER L.R., LUGATO E., BALLABIO C., ALEWELL C., MEUSBURGER K., MODUGNO S., SCHUTT B., FERRO V., BAGARELLO V., OOST V.K., MONTANARELLA L., PANAGOS P. An assessment of the global impact of $21^{\text {st }}$ century land use change on soil erosion. Nat Commun, 8 (1), 2013, 2017.

27. TU H.-M., CHEN H.-M. From deforestation to afforestation: Effect of slopeland use policies on land use/cover change in Taiwan. Land Use Policy, 99, 105038, 2020.

28. WANG Y., YAO S. Effects of restoration practices on controlling soil and water losses in the Wei River Catchment, China: An estimation based on longitudinal field observations. Forest Policy and Economics, 100, 120, 2019.

29. LEWIS W.M. The Ecological Niche in Aquatic Ecosystems, 2009

30. LI Z., SUN X., HUANG Z., ZHANG X., WANG Z., LI S., ZHENG W., ZHAI B. Changes in nutrient balance, environmental effects, and green development after returning farmland to forests: A case study in Ningxia, China. Sci Total Environ, 735, 139370, 2020. 
31. MBAVA N., MUTEMA M., ZENGENI R., SHIMELIS H., CHAPLOT V. Factors affecting crop water use efficiency: A worldwide meta-analysis. Agricultural Water Management, 228, 105878, 2020.

32. LI X., LIU L., QI X., ZHANG J., ZHAO T., WANG Y., LIU X., ZHOU Y. Land use change dynamics and driving forces of the vulnerable ecological region in northwestern Shanxi Province, China. Chinese Journal of Applied Ecology, 25 (10), $2959,2014$.

33. HAO H., HAO Y., REN Z. Analysis on Dynamic and Pattern of Land Use/Cover Change in Guanzhong Area. Scientia Agricultura Sinica, 44 (21), 4525, 2011.

34. WU B., YANG S., SHAO N., PENG R., GUAN Y. Dynamic evolution and driving force analysis of land use/cover change on loess plateau watershed- A case study of Fenhe River Basin. Research of soil and water conservation, 26 (5), 340, 2019.

35. YU X., ZHANG X., NIU L., YUE Y., WU S., ZHANG M. Dynamic evolution and driving force analysis of land use/ cover change on loess plateau watershed. Transactions of the CASE, 25 (7), 219, 2009.

36. YANG H., WANG H., PENG W., REN G. Research of spatial and temporal dynamic changes in regional land use/cover- A case study in Jintang County. Chinese Journal of agricultural resources and regional Planning, 37 (8), 37, 2016.

37. TONG X., YANG Q., BI G. Spatio-temporal Characteristics of Land Use Changes in Chongqing during 2000-2015. Resource and environment in the Yangtze Basin, 27 (11), 2481, 2018.

38. JU F., MA T., GU X., CAI H., WU Y. Analysis of landuse spatio-temporal change in a karst region by dynamic method. Environmental Science \& Technology, 041 (008), 160, 2018.

39. LOU Y., FENG B. Spatial-temporal changes of land use in hilly and plain region: a case study in Deqing County, Zhejiang Province. Scientific and technological management of land and resources, 32 (5), 89, 2015.
40. DONG G., HE L., WANG Y., XIONG R., CHENG W. Study on spatio-temporal pattren of land use change in Yi County, Hebei Province from 1990 to 2017. Chinese Journal of agricultural resources and regional Planning, 41 (1), 242, 2020.

41. SHI L., WANG S., YAO X., NIU J., YU L. Spatial and temporal variation characteristics of land use and its driving force in Shanghai City from 1994 to 2003. Resource and environment in the Yangtze Basin, 21 (12), 1468, 2012.

42. ZHANG J., ZANG C. Spatial and temporal variability characteristics and driving mechanisms of land use in the Southeastern River Basin from 1990 to 2015. ACTA ECOLOGICA SINICA, 039 (024), 9339, 2019.

43. CHEN X., TANG H., WU Y., ZHOU Q., CUI J. Analysis on Process and Difference of Cropland Dynamics in Anji County of Zhejiang Province. Scientia Agricultura Sinica, 48 (21), 4302, 2015.

44. LIU J., ZHAO D., TIAN X., ZHAO L., LIU J. Landscape pattern dynamics and driving forces analysis in the Sanjiang Plain from 1954 to 2010. ACTA ECOLOGICA SINICA, 34 (12), 3234, 2014.

45. TONG G., LIN JIE, CHEN HANG, GU Z., TANG P., ZHANG J. Land use and landscape pattern changes and driving force factors in Nanjing from 1986 to 2013. Research of soil and water conservation, 24 (2), 240, 2017.

46. ABEJE M.T., TSUNEKAWA A., ADGO E., HAREGEWEYN N., BERIHUN D. Exploring Drivers of Livelihood Diversification and Its Effect on Adoption of Sustainable Land Management Practices in the Upper Blue Nile Basin, Ethiopia. Sustainability, 11 (10), 1, 2019.

47. TANG J., LI Y., CUI S., XU L., DING S., NIE W. Linking land-use change, landscape patterns, and ecosystem services in a coastal watershed of southeastern China. Global Ecology and Conservation, 23, e01177, 2020.

48. LEIFELD J. Prologue paper: Soil carbon losses from landuse change and the global agricultural greenhouse gas budget. Science of the Total Environment, 465, 3, 2013. 